\title{
WHO/INRUD drug prescribing indicators at primary health care centres in Eastern province, Saudi Arabia
}

\author{
A.A. ElMahalli
}

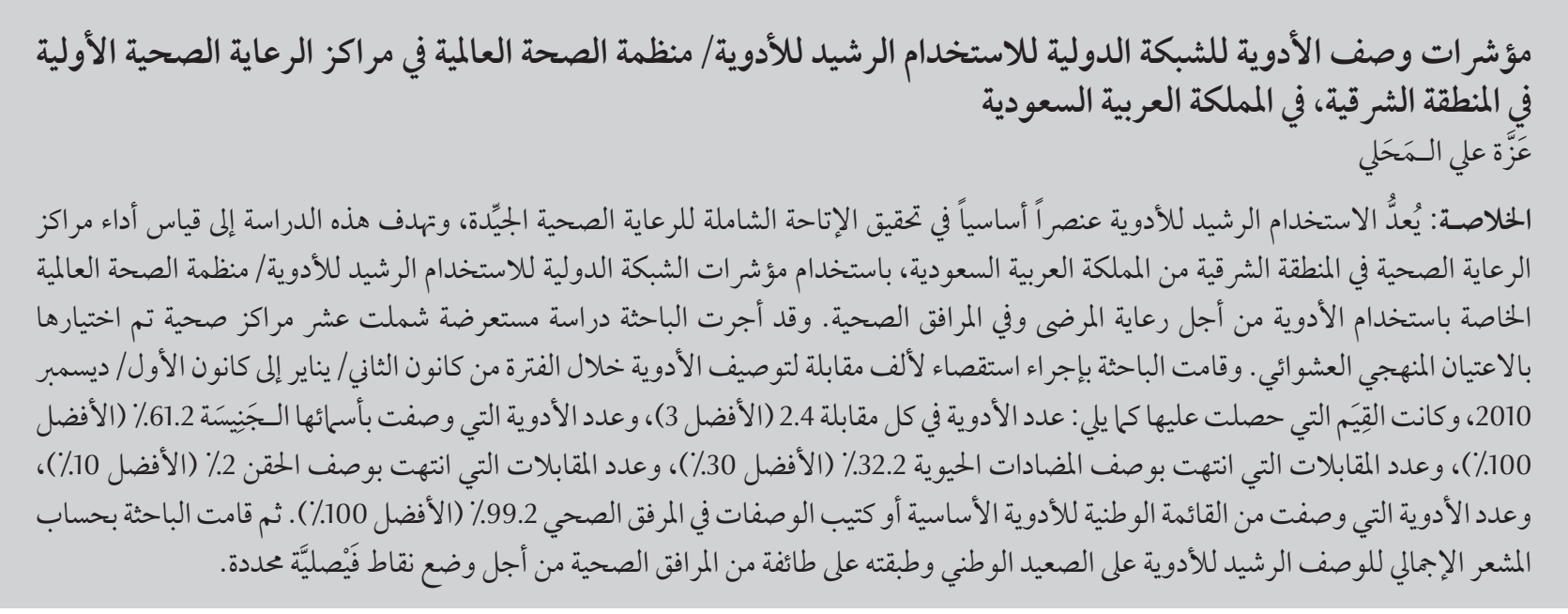

ABSTRACT Appropriate use of drugs is an essential element in achieving quality of health and medical care for patients and the community as a whole. This study aimed to measure the drug prescribing performance of primary health care centres in Eastern province, Saudi Arabia, using the WHO/International Network of Rational Use of Drugs core drug prescribing indicators. In a retrospective cohort study 10 health centres were selected using systematic random sampling. A total of 1000 prescribing encounters were investigated from January to December 2010. Mean values were: number of drugs per encounter 2.4 (optimal $\leq 3$ ), drugs prescribed by generic name $61.2 \%$ (optimal 100\%), encounters with antibiotic prescribed $32.2 \%$ (optimal $\leq 30 \%$ ), encounters with injection prescribed $2 \%$ (optimal $\leq$ $10 \%$ ) and drugs prescribed from the national essential drugs list or facility formulary $99.2 \%$ (optimal 100\%). An overall index of rational drug prescribing was calculated and applied to rank the health centres for benchmarking.

Indicateurs OMS/INRUD pour la prescription médicamenteuse dans des centres de soins de santé primaires de la province orientale de I'Arabie saoudite

RÉSUMÉ Une utilisation appropriée des médicaments est un élément essentiel pour atteindre une qualité des soins médicaux pour les patients et la communauté dans son ensemble. La présente étude visait à mesurer les pratiques de prescription médicamenteuse des centres de soins de santé primaires dans la province orientale de l'Arabie saoudite, à l'aide des indicateurs fondamentaux de prescription médicamenteuse mis au point par l'Organisation mondiale de la Santé et le Réseau international pour l'usage rationnel des médicaments (INRUD). Dans une étude de cohorte rétrospective, dix centres de soins de santé ont été sélectionnés par échantillonnage aléatoire systématique. Au total, 1000 consultations ayant donné lieu à des prescriptions entre janvier et décembre 2010 ont été examinées. Les valeurs moyennes étaient les suivantes : nombre de médicaments prescrits par consultation 2,4 (valeur optimale inférieure ou égale à 3), médicaments prescrits par nom générique 61,2\% (valeur optimale $100 \%$ ), consultations ayant donné lieu à la prescription d'antibiotiques 32,2 \% (valeur optimale inférieure ou égale à $30 \%$ ), consultations ayant donné lieu à la prescription d'une injection $2 \%$ (valeur optimale inférieure ou égale à $10 \%$ ) et prescriptions médicamenteuses à partir de la liste nationale des médicaments essentiels ou de la liste des médicaments utilisés par l'établissement 99,2 \% (valeur optimale $100 \%$ ). Un indice global de prescription rationnelle des médicaments a été calculé puis appliqué pour le classement des centres de soins de santé à des fins de comparaison.

${ }^{\prime}$ College of Applied Medical Sciences, University of Dammam, Dammam, Saudi Arabia; and Department of Health Administration and Behavioural Sciences, High Institute of Public Health, University of Alexandria, Alexandria, Egypt (Correspondence to A.A. El.Mahalli: aelmahalli90@gmail.com). Received: 08/07/11; accepted: 11/01/12 


\section{Introduction}

Appropriate use of drugs is an essential element in achieving quality of health and medical care for patients and the community as a whole [1]. The World Health Organization (WHO) defined rational use of drugs as patients receiving medications appropriate to their clinical needs, in doses that meet their own individual requirements, for an adequate period of time and at the lowest cost to them and their community [2-5]. Irrational use of medicines includes the use of too many medicines (polypharmacy); use of antibiotics for non-bacterial infections; inadequate dosages of antibiotics; use of injections when oral medication is more appropriate; prescribing medicines that contravene clinical guidelines; and patient self-medication [1].The irrational use of medicines is a serious problem worldwide $[2,6-8]$. It can result in adverse drug reactions, increased morbidity and mortality rates, wasted resources and higher out-of-pocket costs to patients. Inappropriate and over-use of antibiotics is a risk for development of antibiotic resistant strains of bacteria [7] and bloodborne infections such as hepatitis and HIV/AIDS can be transmitted by non-sterile injections.

$\mathrm{WHO}$ and the International Network of Rational Use of Drugs (INRUD) have developed a set of drug prescribing indicators to be used as measures of prescribing performance in primary care [1]. To the authors' knowledge, at the time of this study, few studies had been performed in primary care in Saudi Arabia measuring prescribing patterns $[9,10]$. Measured values could be used as benchmarking among health care facilities and as a baseline for ongoing monitoring of the quality of drug prescribing. In an accompanying paper we reported on patient care and facility-specific drug use indicators in 10 primary health care centres (PHCCs) in Eastern province of Saudi Arabia [11]. The objectives of the current study were to use the WHO/INRUD prescribing indicators to assess rational drug prescribing in the same PHCCs. These would be used to identify whether a facility was exceeding or under-performing these defined norms of practice and to obtain baseline information for continuous monitoring.

\section{Methods}

\section{Study design and setting}

This was a retrospective, cohort study carried out in 10 PHCCs from the Eastern province, selected based on systematic random sampling to represent the 13 districts of the province.

\section{Sample}

The sample was the medical records of patients attending the PHCCs and the prescription forms written for the period January to December 2010. A sample of 100 prescribing encounters was selected from each PHCC. Encounters were spread at regular intervals throughout the year using systematic random sampling to minimize bias due to seasonal variations or interruptions of drug supply cycle. Therefore a total of 1000 prescribing encounters were analysed.

\section{Data collection}

Formal approval from the Ministry of Health in Saudi Arabia was taken before conducting the research. Confidentiality of the data collected from medical records was maintained throughout.

A standard prescribing indicators form was used to collect the required variables [1]. Data collectors at all PHCCs followed the WHO guidelines and methods to ensure reliability of data collection. A pilot study was conducted in which 50 prescriptions from 2 different centres were reviewed to ensure the availability of the required data, to estimate the time required to collect the variables and to edit the data collection tool as needed. The following WHO/ INRUD prescribing indicators were used in this study and were calculated using standard methods [1]:

- Average number of drugs prescribed per encounter (whether the patient actually received the drugs or not). Optimal level: $\leq 3$.

- Percentage of drugs prescribed by generic name. Optimal level: 100\%.

- Percentage of patient encounters with an antibiotic prescribed. Optimal level: $\leq 30 \%$.

- Percentage of patient encounters with an injection prescribed. Optimal level: $\leq 10 \%$.

- Percentage of drugs prescribed from the national EDL or the facility's formulary. Optimal level: 100\%.

\section{Data analysis}

To assess rational drug prescribing performance, we used an index system based on the mathematical model developed by Zhang and Zhi for comprehensive appraisal of medical care. The index system has been validated for use in medical and health research [12]. Indices were calculated for each prescribing indicator by dividing the optimal values by the actual values obtained. All the indicators had the same optimal index of 1: the closer to 1 , the more rational a drug use indicator. Then a total index of rational drug prescribing (IRDP) was calculated for each health centre by adding the indices, using the method of Dong et al. [13]. This enabled them to be ranked in order to identify the PHCC with the highest score to be used for benchmarking.

Data entry and analysis were conducted using SPSS, version 19. Descriptive statistics were used in the form of mean, median, and standard deviation (SD). Differences between PHCCs regarding prescribing indicators were tested using analysis of variance (ANOVA). The statistical significance was determined by a $P$-value $<0.05$. 


\section{Results}

The average number of drugs per encounter ranged from 2.0-2.9 across the different PHCCs, with a mean of 2.4 (SD 1.2) for the 10 PHCCs (Table 1).

The percentage of drugs prescribed by generic name varied widely across the PHCCs, from 6.0\%-99.9\% (Table 1 ), with a mean of $61.2 \%$ (SD $45.6 \%$ ). The percentage of encounters with an antibiotic prescribed ranged from $23.0 \%-41.0 \%$, with a mean of $32.2 \%$ (SD 46.7\%), while the rate of injection prescribing covered a smaller range $(0 \%-5.0 \%)$ and the mean was only $2.0 \%$ (SD 14.0\%) (Table 1).

The percentage of drugs prescribed from the EDL or formulary ranged from $96.8 \%-100 \%$, with a mean of $99.2 \%$ (SD 7.6\%) (Table 1).

The difference between the PHCCs was statistically significant for the average number of drugs/encounter, percentage of drugs prescribed by generic name and percentage of drugs prescribed from the EDL or formulary (Table 1).

Among the PHCCs, centre number 10 was ranked the highest for IRDP, meeting the index level in all cases ( $\mathrm{Ta}$ ble 2).

\section{Discussion}

Irrational use of drugs occurs in all countries and causes harm to people $[2,14]$. The results of the present study revealed that the average number of drugs prescribed per encounter was 2.4 and that there were statistically significant differences among the 10 PHCCs (averages ranging from 2.02.9). Although this value was within the acceptable limit proposed in this study ( $\leq 3$ drugs prescribed per patient encounter) and none of the PHCCs were above the cutoff value, data from some other developing countries reported a lower average number of

ஃ 巳 巳巳巳巳巳

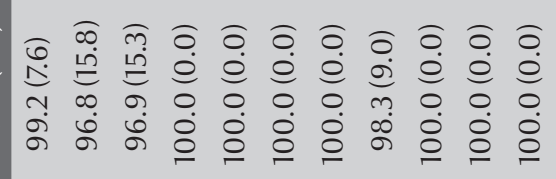

00000000000

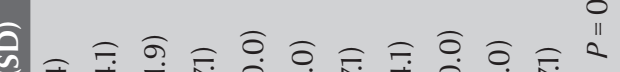

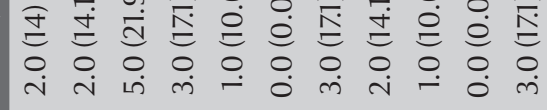
00000000000

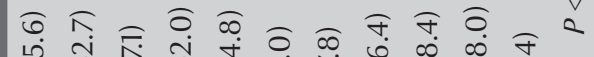

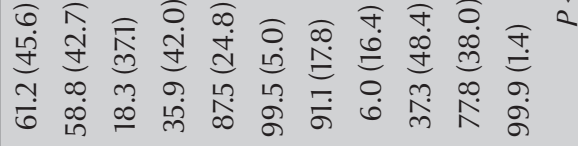




\begin{tabular}{|c|c|c|c|c|c|c|}
\hline \multirow[t]{2}{*}{ Health centre } & \multicolumn{5}{|c|}{ Index ${ }^{a}$} & \multirow[t]{2}{*}{ IRDPb } \\
\hline & Polypharmacy & $\begin{array}{l}\text { Generic name } \\
\text { prescribing }\end{array}$ & $\begin{array}{l}\text { Antibiotic } \\
\text { prescribing }\end{array}$ & $\begin{array}{c}\text { Safe injection } \\
\text { prescribing }\end{array}$ & EDL prescribing & \\
\hline 1 & 1 & 0.59 & 0.81 & 1 & 0.97 & 4.37 \\
\hline 2 & 1 & 0.18 & 1 & 1 & 0.97 & 4.15 \\
\hline 3 & 1 & 0.36 & 1 & 1 & 1 & 4.36 \\
\hline 4 & 1 & 0.88 & 0.88 & 1 & 1 & 4.76 \\
\hline 5 & 1 & 1 & 0.88 & 1 & 1 & 4.88 \\
\hline 6 & 1 & 0.91 & 1 & 1 & 1 & 4.91 \\
\hline 7 & 1 & 0.06 & 0.73 & 1 & 0.98 & 3.77 \\
\hline 8 & 1 & 0.37 & 0.90 & 1 & 1 & 4.27 \\
\hline 9 & 1 & 0.78 & 0.83 & 1 & 1 & 4.61 \\
\hline 10 & 1 & 1 & 1 & 1 & 1 & 5.00 \\
\hline
\end{tabular}

${ }^{a}$ Optimal index $=7 ;{ }^{b}$ Maximum $\operatorname{IRD} P=5$.

$E D L=$ essential drugs list.

drugs per encounter, ranging from $1.3-2.2[15-18]$. In a study conducted in Gaza Strip, the mean number of drugs per prescription was 1.92 [19]. However, in a study carried out in 50 PHCCs across 5 governorates of Kuwait, the mean number of drugs prescribed per prescription was 2.9 [20] and in 4 PHCCs of Bahrain, the average number of drugs per encounter was 2.6 [21]. Rational prescribing is advocated to avoid wastage of medicines and to avoid possible adverse effects to patients. Moreover, prescribing unnecessary medications to patients has cost implications for national health systems.

WHO highly recommends prescribing medications by generic name as a safety precaution for patients because it identifies the drug clearly, enables better information exchange and allows better communication between health care providers [22]. The mean percentage of drugs prescribed by generic name was low (61.2\%) compared with the optimal value (100\%). The difference between PHCCs was statistically significant. This low rate of prescribing by generic name might be due to the high number of expatriate physicians in Eastern province with background experience with different brand-name drugs. This makes information exchange and communication between health care providers more difficult. In other developing countries the rate of generic prescribing was above 59\% [13-16]. However, in PHCC in Gaza Strip, it was only 5.5\% [19] and in Bahrain, the rate of generic prescribing was $14.3 \%$ [21].

The percentage of encounters with an antibiotic prescribed was $32.2 \%$, slightly higher than the optimal value proposed $(\leq 30 \%)$. However, it is difficult to judge whether antibiotics were inappropriately prescribed as this was not part of the study design. In other developing countries, the rate of antibiotic prescribing ranged from $29 \%-43 \%$ [15-18] and in 50 PHCCs across 5 governorates of Kuwait, $39.1 \%$ of prescriptions involved an antibiotic [20]. A study conducted in Egypt comparing the effect of adopting the Integrated Management of Childhood Illness programme on children under 5 years reported that the average percentage of antibiotics prescribed was $45.3 \%$ [23]. The overuse and misuse of antibiotics is threatening the health of populations worldwide [24-27]. Irrational prescribing of antibiotics can lead to adverse reactions and hospital admission for individuals [24] and on a population level there is a risk of emergence of antibioticresistant strains of bacteria [27].
Injections were prescribed in 2.0\% of encounters on average, which was well within the acceptable limit proposed $(\leq 10 \%)$. The rate of prescribing injections was considerably lower than in Kuwait (9.1\%) [20] and Bahrain (8.3\%) [21]. Use of injections when oral formulations are more appropriate is an irrational use of medicines because the cost of injections is always higher than that of oral therapy. Moreover, it increases the risk of bloodborne diseases such as hepatitis and HIV/AIDS being transmitted through the use of non-sterile injections [2].

The mean percentage of drugs prescribed from the national EDL or facility formulary was $99.2 \%$, and the difference between PHCCs was significant. This is similar to studies in Bahrain (99.8\%) [21] and Gaza Strip (97.9\%) [19]. Generally in other developing countries values higher than $80 \%$ have been reported [15-18]. It is expected that $100 \%$ of drugs will be prescribed from the EDL or formulary. Prescribing drugs from the EDL issued by WHO provides a framework for rational prescribing; drugs on the list are well-established drugs, already tested in practice, with established clinical use and lower cost than newer drugs [28]. 
PHCC number 10 had the highest IRDP and ranked 1st among the sampled PHCCs. This centre should be considered as benchmarking for the remaining centres in Eastern province.

The study was limited in that it was not designed to reveal the reasons leading to irrational prescribing of drugs. Future studies are required to investigate these factors. Nevertheless the study had a number of strengths. It was the first study to be conducted in the Eastern province of Saudi Arabia measuring drug prescribing performance at PHCCs. Also data were collected from 10 PHCCs representing the 13 districts of Eastern province and the sample size, 1000 prescriptions, was large. Use of WHO/INRUD core drug prescribing indicators adds strength to the study. Finally, developing the IRDP to measure the degree of rational/irrational drug use would be beneficial for future studies.

\section{Conclusion and Recommendations}

This study measured the drug prescribing performance of PHCCs in Eastern province of Saudi Arabia using the WHO/INRUD core drug prescribing indicators. The results showed that the average number of drugs prescribed per encounter and the percentage of encounters with injections prescribed were within the optimal values proposed in this study. However, the percentage of drugs prescribed by generic name was far from the optimal value. Also, the percentage of encounters with antibiotics prescribed was slightly higher than the optimal and the percentage of drugs prescribed from the EDL or formulary was less than optimal. We recommend that physicians working at PHCCs need continuous education about rational prescribing of antibiotics and motivation to prescribe drugs by generic name and from the EDL/ formulary list. Future studies are needed to investigate the reasons behind the irrational use of drugs. Consideration should be given to using the highest ranked health centre as a benchmark for other PHCCs in the region.

\section{Acknowledgements}

This project could not have been realized without the support of the data collectors.

\section{References}

1. How to investigate drug use in health facilities: selected drug use indicators. Geneva, World Health Organization, 1993 (EDM Research Series No. 007).

2. Medicines: rational use of medicines. Fact sheet No. 338. World Health Organization [online] (http://www.who.int/mediacentre/factsheets/fs338/en/, accessed 16 September 2012).

3. Zarmba S. Uganda national communication strategy for promoting rational use of medicine. Kampala, Uganda, Ministry of Health, 2009 (http://apps.who.int/medicinedocs/documents/s16511e/s16511e.pdf, accessed 16 September 2012).

4. Rational use of medicines by prescribers and patients. Geneva, World Health Organization, 2005.

5. Bhartiy SS et al. Pattern of prescribing practices in the Madhya Pradesh. Kathmandu University Medical Journal, 2008, 6:55-59.

6. Bhatt SP. Rational use of medicine. International Journal of Pharmaceutical Research, 2010, 2:69.

7. Irrational drug use causing rise of anti-microbial resistance. Geneva, World Health Organization, 2005.

8. Asif I. Irrational use of medicine: a threat to patient community. Ezine [online article] (http://ezinearticles. com/? Irrational-Use-of-Medicines---A-Threat-to-PatientCommunity\&id=3144554, accessed 16 September 2012).

9. Mahfouz AA et al. Prescribing patterns at primary health care level in the Asir region, Saudi Arabia: an epidemiologic study. Pharmacoepidemiology and Drug Safety, 1997, 6(3):197-201.

10. Al-Nasser AN. Prescribing patterns in primary healthcare in Saudi Arabia. DICP: the Annals of Pharmacotherapy, 1991, 25(1):90-93.

11. El Mahalli AA et al. WHO/INRUD patient care and facilityspecific drug use indicators at primary health care centres in Eastern province, Saudi Arabia. Eastern Mediterranean Health Journal, 2012, 12(11):1086-1090.
12. Zhang Y, Zhi M. Index system, appraising method for comprehensive appraisal. Journal of North Jiaotong University, 1995, 19:393-400.

13. Dong L. Yan H, Wang D. Drug prescribing indicators in village health clinics across 10 provinces of western China. Family Practice, 2010, 28:63-67.

14. Session guide. Implementing a drug use indicators study. World Health Organization [online] (http://archives.who.int/prduc2004/rducd/Session_Guides/implementing__sg.htm, accessed 18 September 2012).

15. Bannenberg WJ et al. Evaluation of the Nile province essential drugs project. Geneva, World Health Organization, 1991 (WHO/DAP/91.10).

16. Ofori-Adjei D. Report on Tanzania field test. INRUD News, 1992, 3:9.

17. Hogerzeil HV et al. Impact of an essential drugs program on availability and rational use of drugs. Lancet, 1989, 1:141-142.

18. Bimo. Report on Nigeria field test. INRUD News, 1992, 3:9-10.

19. Fattouh R, Abu Hamad B. Impact of using essential drug list: analysis of drug use indicators in Gaza Strip. Eastern Mediterranean Health Journal, 2010, 16(8):886-892.

20. Awad A, Al-Saffar N. Evaluation of drug use practices at primary healthcare centers of Kuwait. European Journal of Clinical Pharmacology, 2010, 66(12):1247-1255.

21. Naseeb TA, Nasser MA. Drug prescribing indicators in primary health care centers in Bahrain. Saudi Medical Journal, 2005, 26(9):1436-1438.

22. Guidelines on the use of international nonproprietary names (INNs) for pharmaceutical substances. Geneva, World Health Organization, 1997 (http://apps.who.int/medicinedocs/ en/d/Jh1806e/, accessed 18 September 2012).

23. El Mahalli AA, Akl OA. Effect of adopting integrated management of childhood illness guidelines on drug use at a primary 
health care center: a case study from Egypt. Journal of Family and Community Medicine, 2011, 18:118-123.

24. Wiffen $\mathrm{P}$ et al. Adverse drug reactions in hospital patients: a systematic review of the prospective and retrospective studies. Bandolier Extra, 2002, June [online] (http://www.medicine. ox.ac.uk/bandolier/Extraforbando/ADRPM.pdf, accessed 18 September 2012).

25. Antimicrobial resistance. World Health Organization [online] (http://www.euro.who.int/en/what-we-do/health-topics/ disease-prevention/antimicrobial-resistance/antibiotic-resistance, accessed 18 September 2012).

26. The world medication situation 2011: rational use of medication. Geneva, World Health Organization, 2011.

27. Irrational drug use causing rise of anti-microbial resistance. Geneva, World Health Organization, 2005.

28. The use of essential drugs. Seventh report of WHO Expert Committee (including the revised model list of essential drugs). Geneva, World Health Organization, 1997.

\section{Good practices in delivery of primary health care in urban settings}

Rapid urbanization and its economic, social, environmental and health impacts affect all countries and regions of the world, particularly developing countries. This report was prepared by the WHO Regional Office for the Eastern Mediterranean, in collaboration with the WHO Centre for Health Development, Kobe, Japan. The report documents good practices in urban health care delivery from the Islamic Republic of Iran, Jordan and Oman which can be used by health system policy-makers, city planners, mayors, governors, midlevel managers, nongovernmental organizations and members of academia as evidence for advocacy and raising political commitment to improve health care delivery in urban settings.

This publication is available on line at: http://applications.emro.who.int/dsaf/EMPUB_2012_865.pdf 